\title{
Breakaway of a motor vehicle from skidding with the use of friction material on public and toting roads
}

\author{
Mikhail Boyarshinov ${ }^{1}$, Vitaliy Zadvorov ${ }^{1}$, Andrey Kochetkov ${ }^{1,}{ }^{*}$, Leonid Yankovskiy ${ }^{1}$, and \\ Vladislav Chudinov ${ }^{1}$ \\ ${ }^{1}$ Perm National Research Polytechnic University, 614990, Permskiy kray, Perm, Komsomolskiy \\ prospekt. 29
}

\begin{abstract}
The goal of the paper is to provide breakaway of a motor vehicle from skidding with the use of friction material on public and toting roads. The development of an anti-skid device is reasonable because road services are not always able to maintain the proper road conditions due to overall highway mileage which leads to road icing and snow knurling, which in turn lowers the friction coefficient of tires with the road. Model analysis and practical experiments are carried out to model breakaway modes while using friction material. This process can be automated for the use in off-road vehicles with a dedicated device that will deliver large grained friction material. The mentioned device had been developed by the authors of the paper. A technical effect of increased adhesion coefficient is achieved within the research. This effect allows the increase in transportation reliability under difficult meteorological and road conditions on public and toting roads. Practical experiments showed that addition of large grain friction material when skidding modifies the surface in front of the tire into a segmented area (angled surface) that helps the vehicle to breakaway and move further without skidding.
\end{abstract}

\section{Introduction}

Effective operation of motor vehicle in various meteorological conditions heavily depends on special road maintenance $[1,2]$.

The research indicates that of the main strategies to increase vehicle off-road capability is to increase the adhesion capabilities of the vehicle drive wheels, which can be achieved with special devices [3-5].

Devices that provide increased adhesion of the drive wheels to the terrain, lowering of the pressure of the tire on the terrain and self-extraction of stuck vehicles are called means of improving passability of terrain.

Winter climate causes snow-and-ice bodies to form and snow to knurl on the road pavement. That leads to decreased adhesion of vehicle tires to the road and consequent poor traffic conditions [6-9].

* Corresponding author: soni.81@mail.ru 
The problem is spread throughout most of Russian regions as well as other countries. A survey on necessity of use of antiskid devices held among heavy construction machinery drivers showed that in winter problems often occur even on well-known roads which in turn leads to lose of traction and skidding.

A loss of traction also occurs on steep inclines covered in ice and leads to traffic congestions and jams.

Standard antiskid devices and methods include trucks, textile covers, belts, chains, bracelets (chains with belts); deflation of tire pressure; snow removal; sand (salt-sand mixtures); salt.

The authors propose to use the developed sand dispersion device installed on the body or the chassis of the vehicle to increase adhesion coefficient between tires and road surface, ensure breakaway from skidding and improvement of off-road capability. The device may function in manual or automatic modes for delivery of friction material under the drive wheels of cars as well as construction and other heavy machines with suspended drivetrains [10].

Research goal is to provide breakaway from skidding in difficult road conditions for cars as well as construction and other heavy machines with suspended drivetrains with the use of a sandblasting device to increase the tire to road adhesion coefficient in difficult weather conditions [2].

\section{Research method}

The research resulted in the development of the prototype of an anti-skid device that was tested in pilot conditions with an imitation of installation to a suspended wheeled excavator through a connection to a stationary air-compressor [10].

The authors propose to use the developed sand dispersion device installed on the body or the chassis of the vehicle to increase adhesion coefficient between tires and road surface, ensure breakaway from skidding and improvement of off-road capability. The device may function in manual or automatic modes for delivery of friction material under the drive wheels of cars as well as construction and other heavy machines with suspended drivetrains.

The development of an anti-skid device is reasonable because road services are not always able to maintain the proper road conditions due to overall highway mileage which leads to road icing and snow knurling which in turn lowers the friction coefficient of tires with the road. This may be witnessed annually on the roads of the Russian Federation from October to April.

Prototype friction material delivery device developed by V.Y. Zadvornov is presented in Figure 1 [10]. 


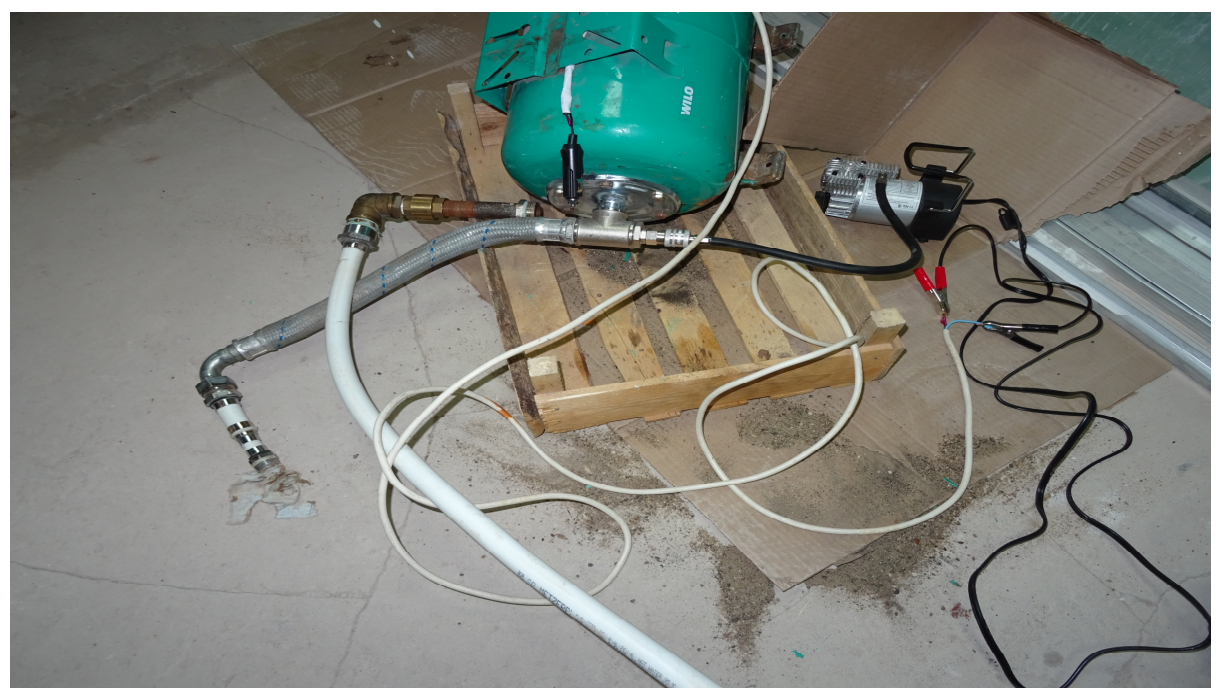

Fig. 1. Prototype device that delivers friction material to the skid zone.

The device consists of friction material canister; car compressor; electrical wire with $12 \mathrm{~V}$ socket; t-connector; elastic hose; connecting box; reverse valve; reinforced plastic pipes.

The scheme of sand delivery under the tire is presented in Figure 2.

Sand delivery device (SDD)

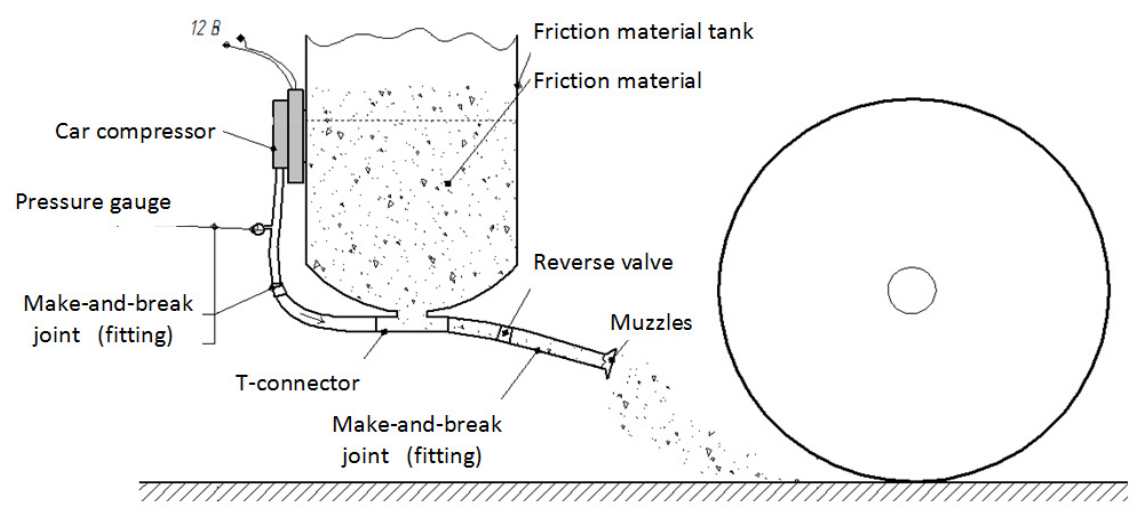

Fig. 2. Schematics of sand delivery under the tire.

After the systems gets filled with air to working pressure, it is possible to open electromagnetic valves to let the air sand mixture through abrasion-proof pipes to the muzzle in order to disperse the mixture with 1.5-2 atmospheres of pressure. The mixture then starts to cut through the ice, blowing out snow masses and creating an area of high friction which, as mentioned before, increases adhesion between tire and road as presented in Figure 3. 


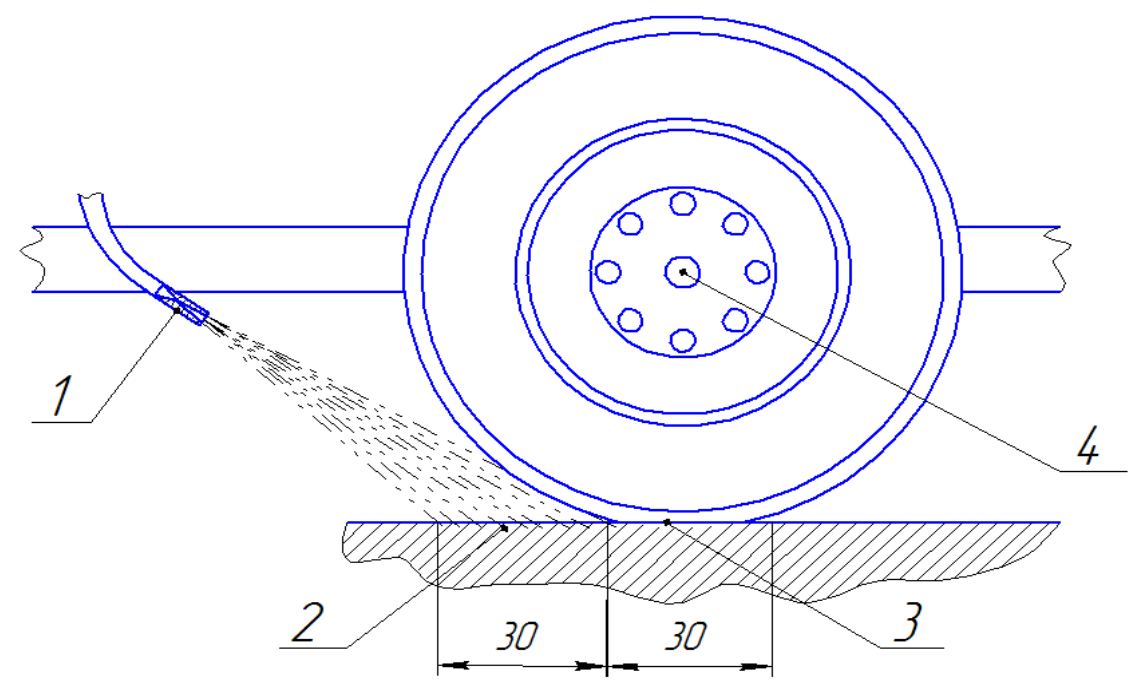

1 - muzzle, 2 - dispersion area of antiskid materials,

3 - tire contact area, 4 - wheel

Fig. 3. area of contact of tire and air-sand mixture.

Mathematical models of movement over different road obstacles are discussed further (Figure 4).

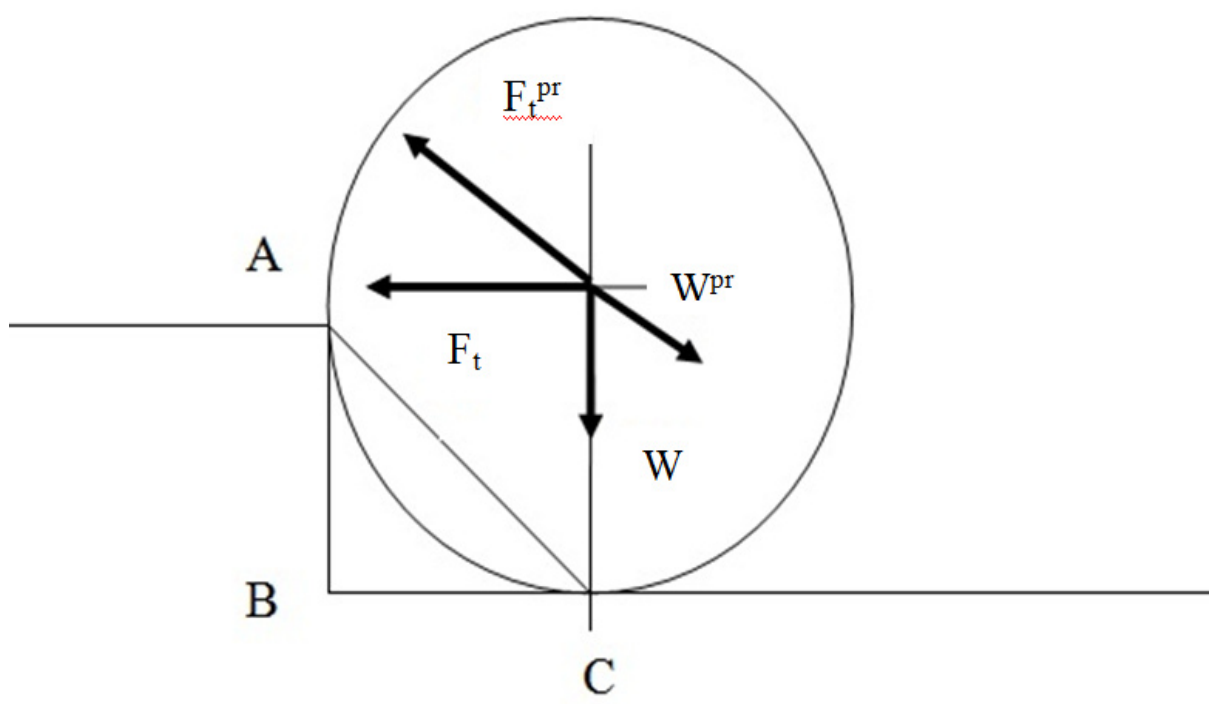

Fig. 4. mage-force model for movement over an obstacle $(\mathrm{AB}$ - obstacle height; $\mathrm{ABC}$ - inclination cone; $\mathrm{AC}$ - inclination line; $\mathrm{F}_{\mathrm{t}}-$ car thrust; $\mathrm{F}_{\mathrm{t}}^{\mathrm{pr}}$ - projection on inclination line $\mathrm{AC} ; \mathrm{W}$ - car weight per wheel; $\mathrm{W}^{\mathrm{pr}}$ - projection of car weight per wheel on $\mathrm{AC}$ ).

A car can move over an obstacle if $\mathrm{F}_{\mathrm{t}}^{\mathrm{pr}}>\mathrm{W}^{\mathrm{pr}}$.

Weight per wheel $\mathrm{W}$ is a constant for every car. Thrust is: 
$\mathrm{F}_{\mathrm{t}}=\mu \mathrm{F}_{\mathrm{e}}$

where $F_{t}-$ car thrust; $\mu$-adhesion coefficient; $F_{e}$ - force reached by the engine in the direction of movement. In turn (without performance coefficient)

$\mathrm{F}_{\mathrm{t}}=\mathrm{N} / \mathrm{v}$

here $\mathrm{N}$ - engine power, $\mathrm{v}$ - speed of movement over obstacle.

$F_{e}$ is constant, $\mu$ - depends on road condition. Projection of $F_{t}$ and $\mathrm{W}$ on the inclination line is defined as:

$\mathrm{F}_{\mathrm{t}}^{\mathrm{pr}}=\mathrm{F}_{\mathrm{t}} \cos (\mathrm{ACB})$

and

$\mathrm{W}^{\mathrm{pr}}=\mathrm{W} \cos (\mathrm{ACB})$,

Here ACB - wheel ascending angle over the obstacle, and $\mathrm{F}_{\mathrm{fr}}$ - force of friction.

Capabilities of the vehicle to overcome an obstacle decrease with the increase of the height of an obstacle (and corresponding wheel ascending angle) because projection of thrust $\mathrm{F}_{\mathrm{t}}^{\mathrm{pr}}$ decreases, when resistance $\mathrm{W}^{\mathrm{pr}}$ - increases.

The problem of getting out of a snow pit is very similar to the problem of overcoming a rectangular obstacle, with the only major difference in the shape of the front edge (rectangular vs. sectoral), as presented in Figure 5.

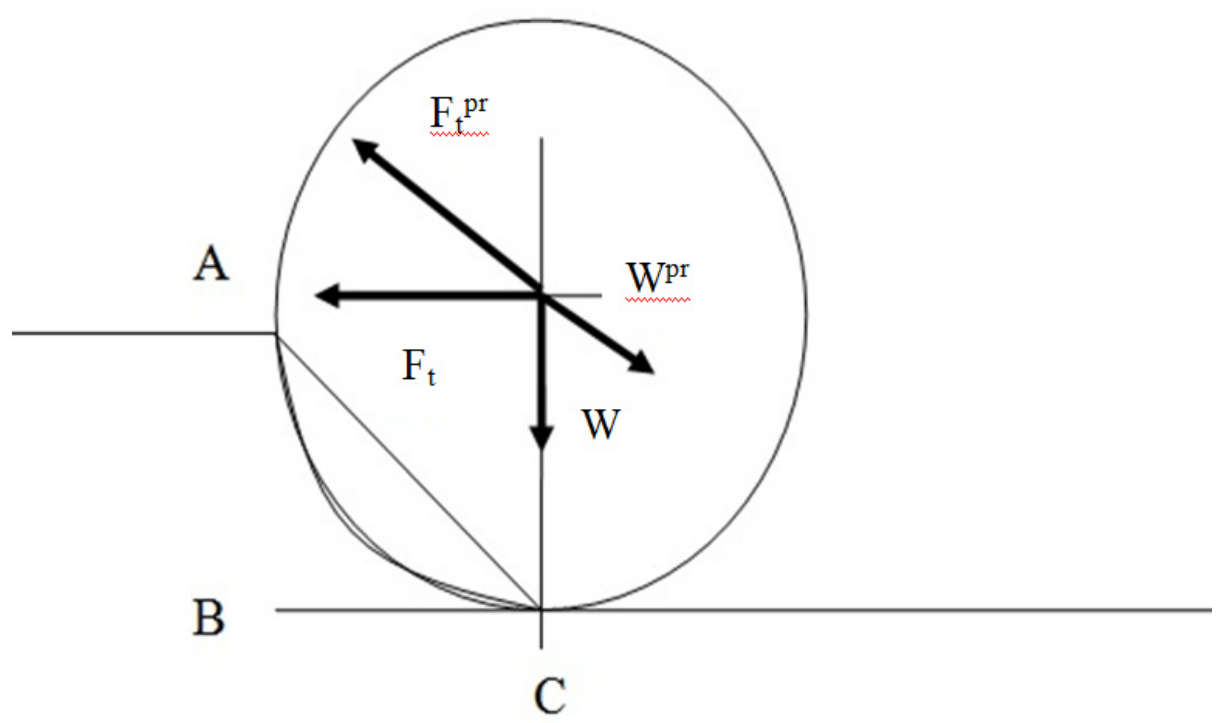

Fig. 5. Image-force model for movement out of a snow pit (symbols are the same as in figure 1).

To move over an obstacle like deep snow, one can use heaping of snow with particulate matter such as sand.

The technology involves backward movement of the vehicle with simultaneous dispersion of sand through metering-muzzles under the tires. (Figure 6 and 7). 


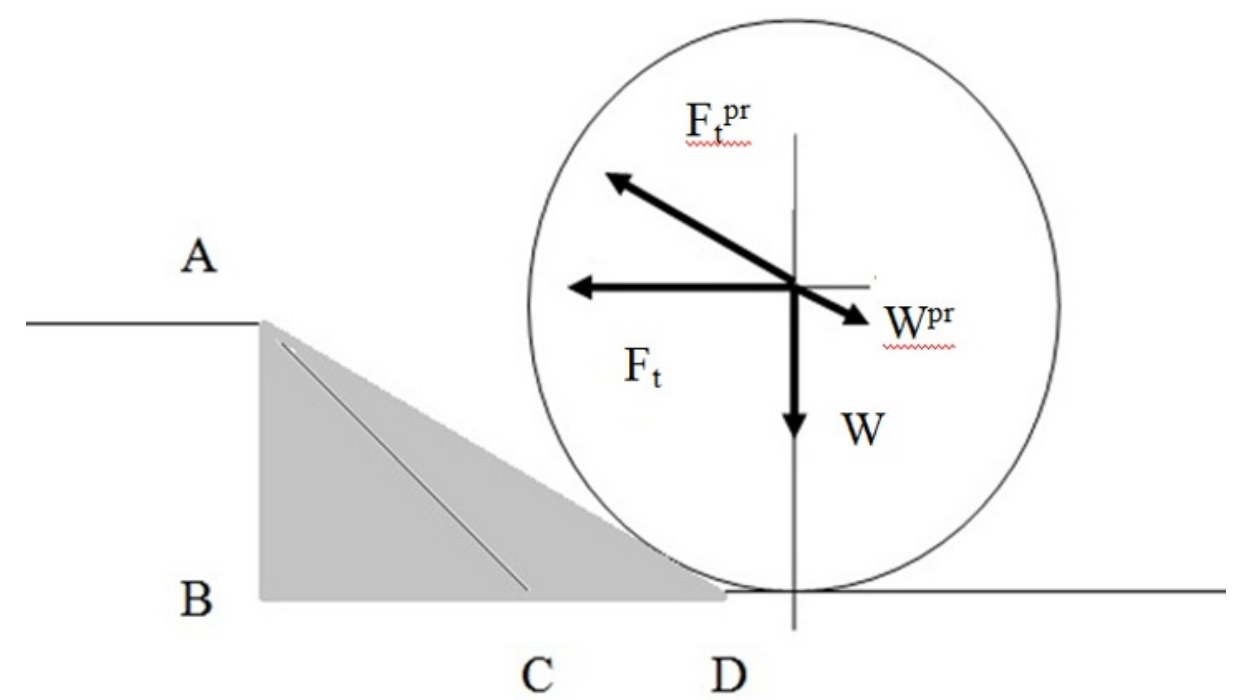

Fig. 6. Movement over a rectangular obstacle using sand heaping (heaping zone is darkened).

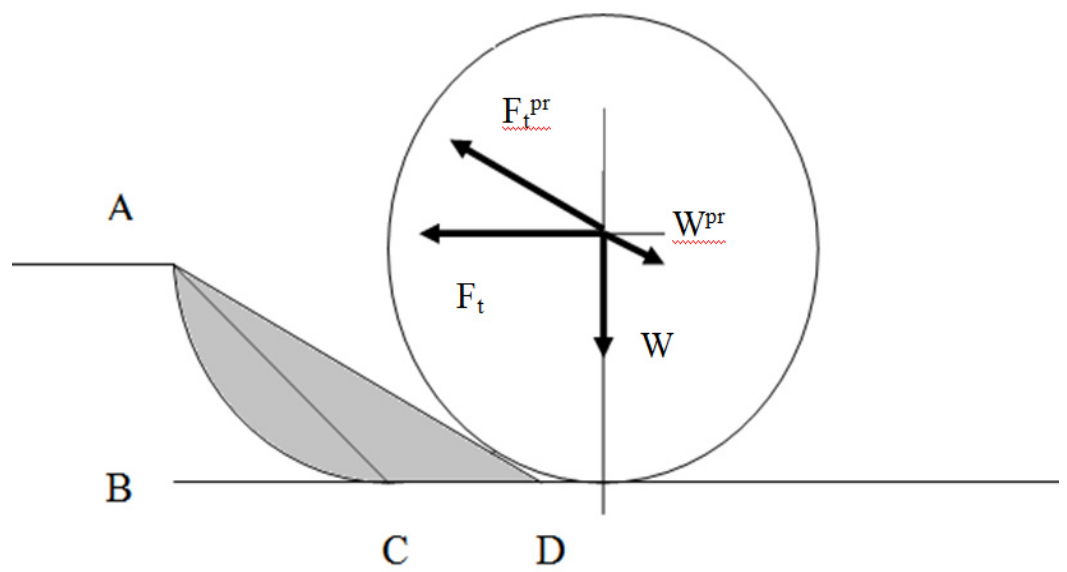

Fig. 7. Getting out of a snow pit using sand heaping (heaping zone is darkened).

Both figures 6 and 7 illustrate that angle ADB is less steep than ACB, which correlates to the steeper inclination lines providing for a more optimal conditions for movement over an obstacle. Thus, with heaping $\mathrm{F}_{\mathrm{t}}^{\mathrm{pr}}$ would be bigger, and $\mathrm{W}^{\mathrm{pr}}$ would be lower.

The real goal of calculation of optimal conditions for getting out of pits and moving over obstacles would comprise of achieving the minimal required distance of rollback from the obstacle based on specific parameters of the vehicle: wheel radius, obstacle height, adhesion coefficient, vehicle thrust and distributed weight of the vehicle.

The result of this calculation should indicate the maximal possible angle for successful movement over the obstacle that can be achieved by the vehicle.

Calculation example. 
Input data: car model VAZ-2101. Power $\mathrm{N}=47.2 \mathrm{~kW}$ (64 1.s.). Wheel diameter $\mathrm{D}-590$ $\mathrm{mm}$. Vehicle weight (dry $955 \mathrm{~kg}$ ). For calculation purposes $\mathrm{W}=1055 \mathrm{~kg}=10.346 \mathrm{kN}$. Snow pit height $=15 \mathrm{~cm}$.

\subsection{Without heaping}

Angle $-\arcsin (0.15 / 0.295)=30.560$. Vehicle thrust at speed $\mathrm{v}=5 \mathrm{~km} / \mathrm{h}=1.39 \mathrm{~m} / \mathrm{s}$. Horizontal $\mathrm{Ft} 0=\mathrm{N} / \mathrm{v}=33.96 \mathrm{kN}$. Over snow $\mu=0.22$. Vehicle horizontal thrust $\mathrm{Ft}=7.47$ $\mathrm{kN}$. Projection of thrust force on the incline Ftpr $=\mathrm{Ftcos}(30.560)=6.432 \mathrm{\kappa N}$.

Weight projection $\mathrm{W}^{\mathrm{pr}}=\mathrm{W} \sin \left(30.56^{0}\right)=5.26 \mathrm{kN}$.

Because $\mathrm{F}_{\mathrm{t}}^{\mathrm{pr}}>\mathrm{W}^{\mathrm{pr}}$, (vehicle thrust is greater than weight projection on the incline) the vehicle is able to move out of this snow pit without sand heaping.

\subsection{Different example}

Input data is the same except for the snow pit height which is $29 \mathrm{~cm}$. Than inclination angle is 79.4360 .

Projection of vehicle thrust $\mathrm{F}_{\mathrm{t}}^{\mathrm{pr}}=\mathrm{F}_{\mathrm{t}} \cos \left(79.436^{0}\right)=1.369 \mathrm{kN}$.

Projection of weight $\mathrm{W}^{\mathrm{pr}}=\mathrm{W} \sin \left(29.44^{0}\right)=10.17 \kappa \mathrm{N}$.

Because $\mathrm{F}_{\mathrm{t}}^{\mathrm{pr}}<\mathrm{W}^{\mathrm{pr}}$ (vehicle thrust is less than weight projection on the incline) the vehicle is not able to move out of this snow pit without sand heaping.

\subsection{With sand heaping}

Second example but with sand heaping.

The vehicle rolls back for $10 \mathrm{~cm}$ and disperses sand.

Inclination angle over the sand heap is $47.24^{\circ}$. With the same parameters from the previous example, projection of vehicle thrust is $\mathrm{F}_{\mathrm{t}}^{\mathrm{pr}}=\mathrm{F}_{\mathrm{t}} \cos \left(47.24^{0}\right)=5.07 \mathrm{kN}$.

Weight projection is $\mathrm{W}^{\mathrm{pr}}=\mathrm{W} \sin \left(47.24^{0}\right)=7.60 \mathrm{kN}$.

Because $\mathrm{F}_{\mathrm{t}}^{\mathrm{pr}}<\mathrm{W}^{\mathrm{pr}}$ (vehicle thrust is less than weight projection on the incline) the vehicle is not able to move out of this snow pit without sand heaping.

Let us use the same example, but this time the car will roll back $25 \mathrm{~cm}$, and the device will disperse more sand. Angle of incline over the sand heap is $47.24^{\circ}$ now. Projection of vehicle thrust is $\mathrm{F}_{\mathrm{t}}^{\mathrm{pr}}=\mathrm{F}_{\mathrm{t}} \cos \left(47.24^{0}\right)=6.32 \mathrm{kN}$.

Weight projection is $\mathrm{W}^{\mathrm{pr}}=\mathrm{W} \sin \left(47.24^{0}\right)=5.5 \mathrm{kN}$. Since $\mathrm{F}_{\mathrm{t}}^{\mathrm{pr}}>\mathrm{W}^{\mathrm{pr}}$, i.e. vehicle thrust is greater than weight projection on the incline, the vehicle is able to move out of this snow pit.

\section{Results of the field experiment}

The area of dispersion of antiskid abrasive material is approximately $30 \mathrm{~cm}$ in diameter in case the device is mounted in 1 meter away from the wheel and in $45 \mathrm{~cm}$ above the terrain level.

Air temperature $-13^{\circ} \mathrm{C}$.

A modified road laboratory ADK-M FGUP "ROSDORNII" was used to carry out the experiment. The laboratory was capable to carry out following measurements: covered length, velocity, lateral and transverse inclines of the road, curve radius in plan and longitudinal profile; smoothness of road pavement including IRI; registration of main objects of traffic; video capture of road surface with road length synchronization and 
position; analysis of road pavement condition; adhesion coefficient; depth of tracks in the road pavement; widths and conditions assessment of road pavement (using georadar) [10].

Preparation of snow pits was carried out as follows:

- a car drove to the closed-out area of experiment that was indicated with yellow road cones;

- parking brake was engaged;

- engine was set into 1 gear;

- one of the drive wheels began to spin with twice the speed because of the engaged drivetrain differential;

- these actions quickly produced a circular hole in ice cover

- transmission was then set to neutral, engine was kept running, parking brake was disengaged;

- car moved backward 2-3 $\mathrm{m}$ in reverse gear;

- the produced hole was then measured and photographed (Figure 8);

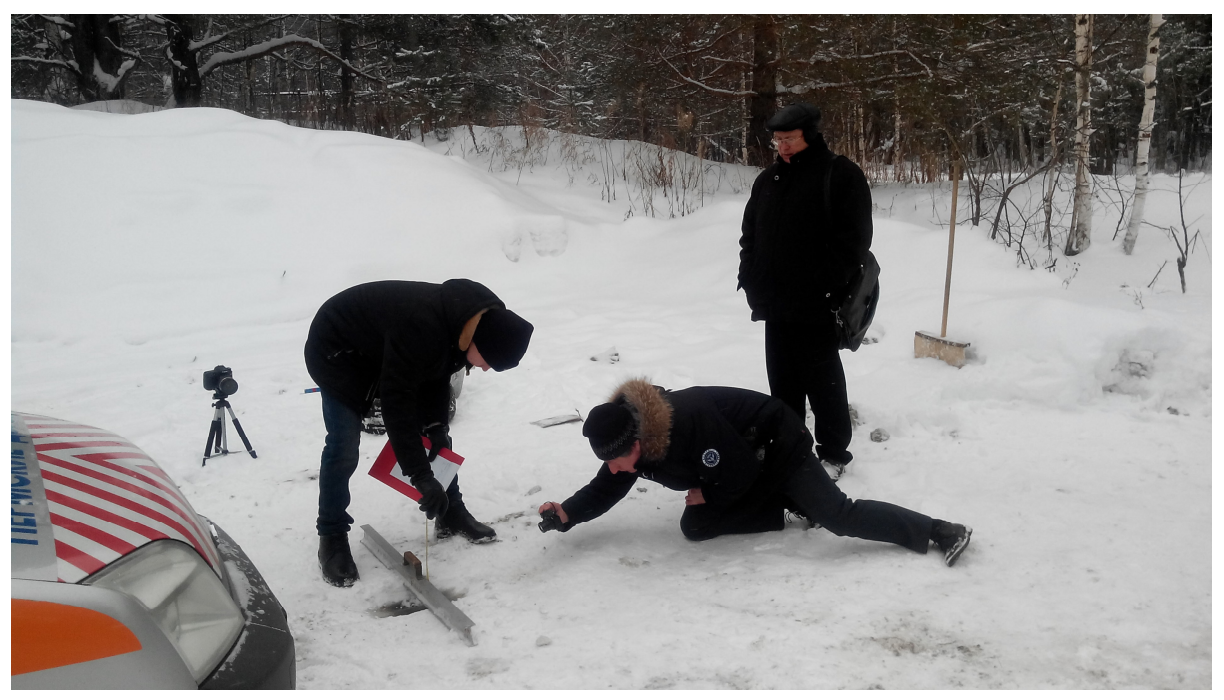

Fig. 8. Measurements of the first hole.

- then a second similar hole was produced for the wheel that was not spinning;

- both holes had a full contact area with the asphalt;

- water was then dispersed over inner walls of the hall in even manner;

- the team than waited 10-15 minutes for the ice to form (Figure 9); 


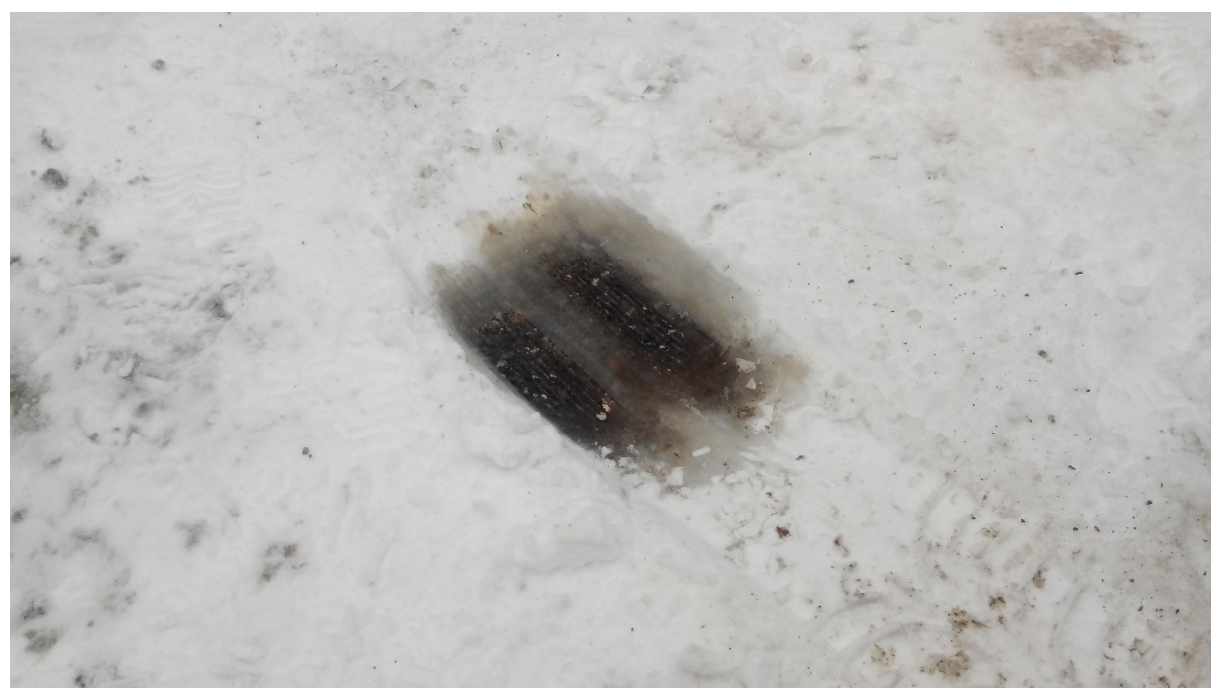

Fig. 9. Ice buildup over the pothole.

- after that, the vehicle slowly rolled into the holes shutting down the engine.

Next, the experiment was carried out with the following results:

- engine was set into first gear with no parking brake engaged and the car couldn't get out of the holes, even though they were only $6 \mathrm{~cm}$ deep. The car was definitely stuck.

- then the engine was stopped, with a cone shaped wall of the hole formed by the skidding of the drive wheel;

- large grain material was injected into the cone shaped area with a measurement shovel in one portion (Figure 10);

- the engine was started again, and the driver tried to move out of the pit;

- quantitative finding - when the dosage of material was low (187 g) the wheel kept spinning with twofold speed and all of the material was thrown away by the wheel. The car was still skidding;

- after that the engine was stopped and all of the preparations were carried out once again in a different spot (following the scheme above);

- in several tries the team established the required amount of material $(387 \mathrm{~g})$. That amount was sufficient for the car to be able to get out of the pit. The car moved right away, without skidding and throwing of material, which stayed in place of dispersion (Figure 11). 


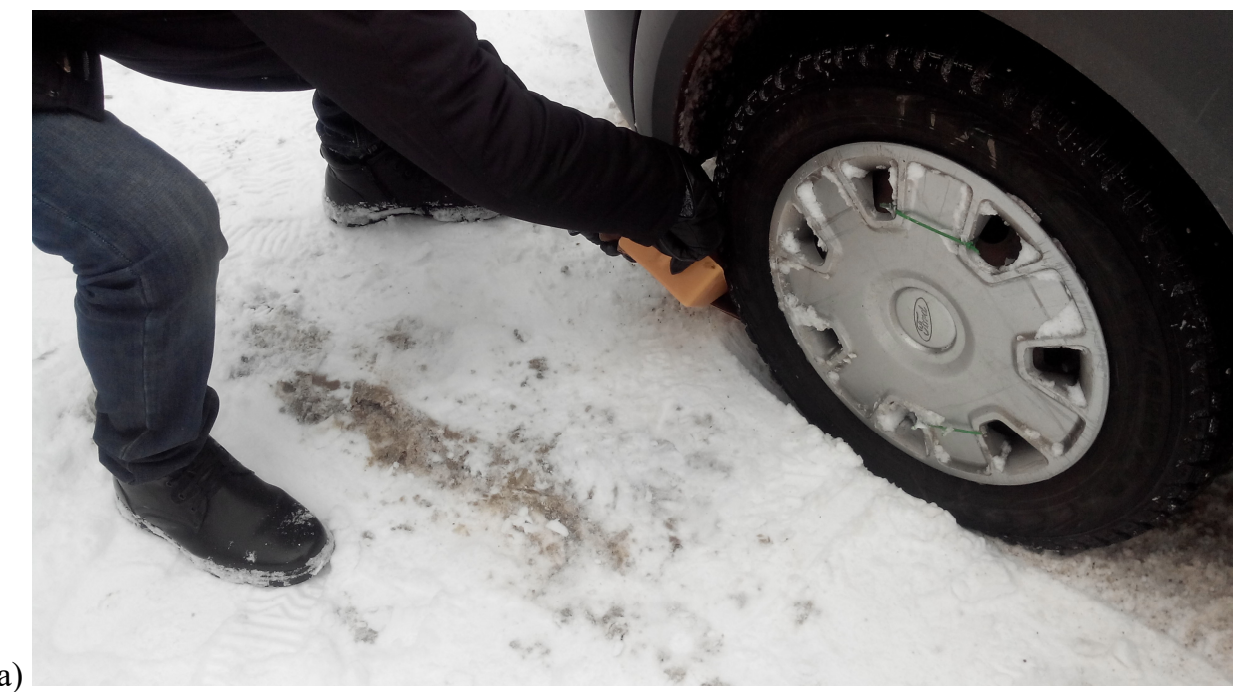

a)

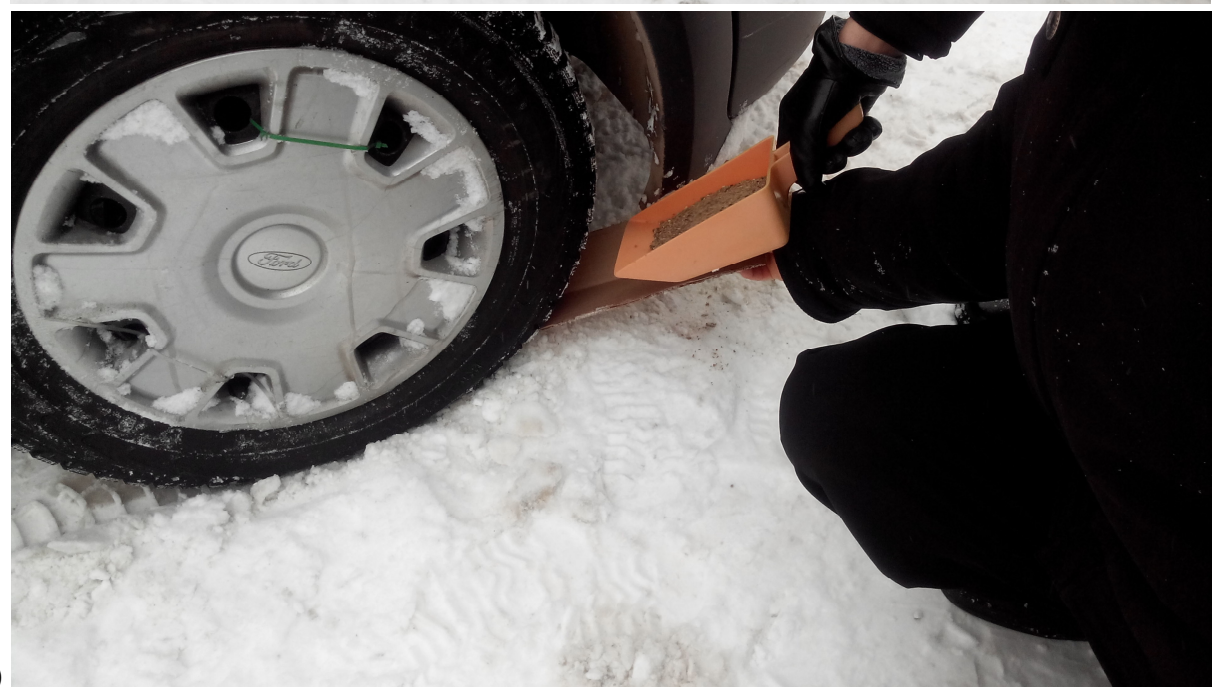

Fig. 10. addition of friction material: a) - left wheel; b) - right wheel. 
a)

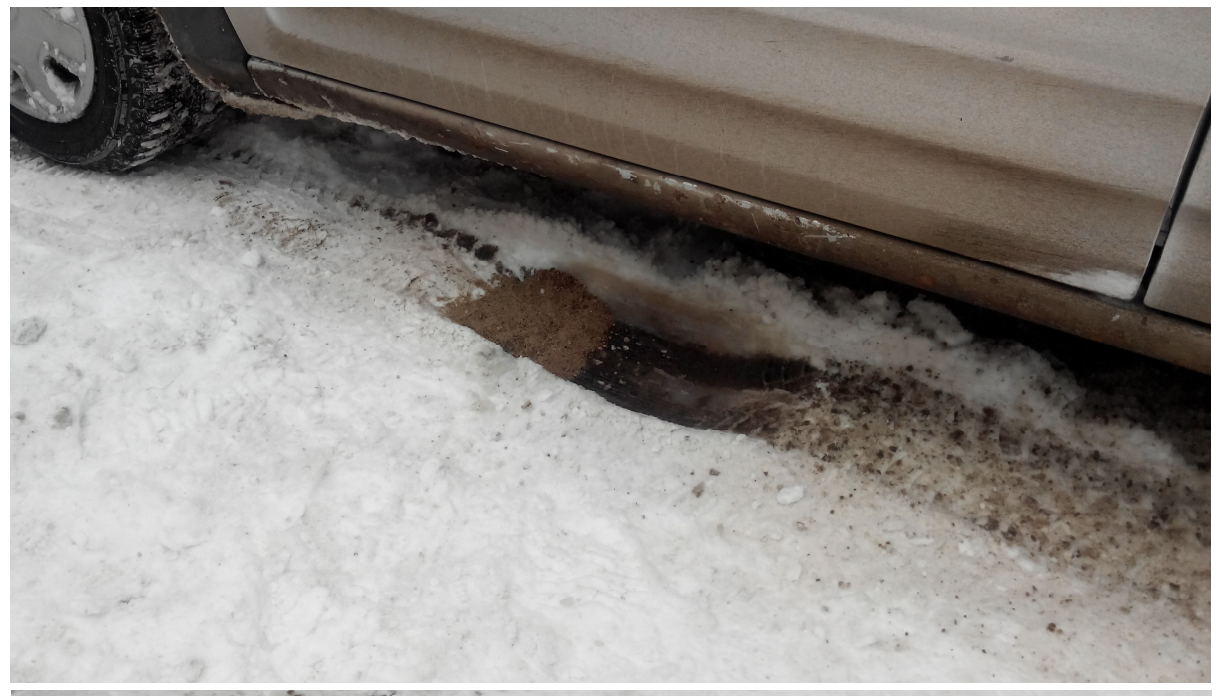

b)

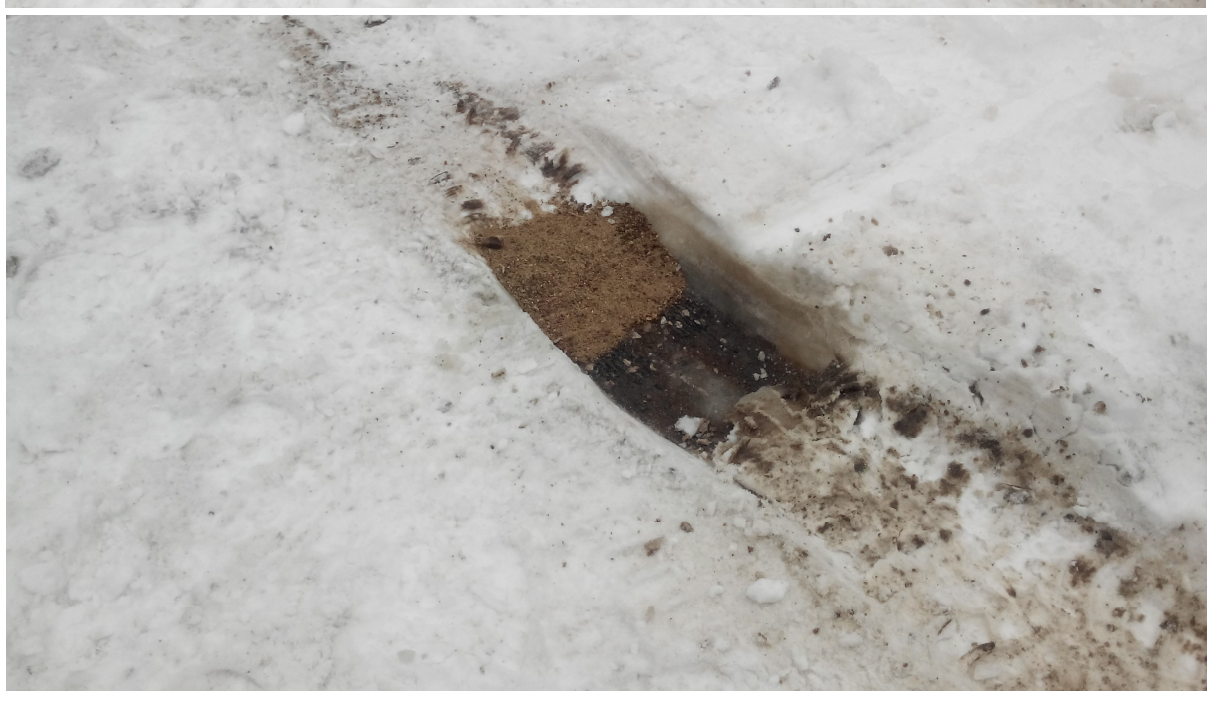

Fig. 11. Car getting out of the pit with the heaping: a) - left pit; b) - right pit.

\section{Research results}

Besides the main experiment, two more were carried out. Both supported the initial results of skidding and getting out of the pits:

- skidding in bigger depth of $0.15 \mathrm{~m}$. In that case, a single dose of $5600 \mathrm{~g}$ of material was required to stop skidding.

- skidding on an incline. In that case, holes were not produced. Instead, the team created an artificial incline of 10 degrees with the car starting from the middle of the incline. In that case, a single dose of $1120 \mathrm{~g}$ of material was required to stop skidding.

Results of the field experiment indicated that adding of large grain friction material modifies the smooth surface in front of the wheel into a sort of segmented area (hill) (Figure 11). That allows the car to move over a snowy terrain without skidding.

That process can be automated for cars and off-road vehicles with the use of the large grain friction material dispersion device developed by the authors of the paper [10]. 


\section{Discussion of results}

1.Experiment algorithm allowed for sufficient reproducibility of the measured results of researched skidding parameters.

2.A clear picture of skidding and hole formation process was captured, with accompanying understanding of decrease in adhesion coefficient.

3.Exact amounts and qualitative parameters of friction material required to stop skidding and getting out of the pit were established.

\section{References}

1. V.I. Greentsevitch, Technical operation of motor vehicles. Tech. calc.: Stud. guide, p.194. Krasnoyarsk, SFU (2011)

2. V.U. Zadvornov, A.V. Kochetkov, L.V. Yankovskiy, A motor vehicle system for crossing of slippery services. Utility model patent № 187658, 8 (2019)

3. R. Martin, I. Cervantes et al., Robust indirect-defined envelope control for rollover and lateral skid prevention Control Engineering Practice. 61, 149-162 (2017)

4. I. Novikov, D. Lazarev, Experimental Installation for Calculation of Road Adhesion Coefficient of Locked Car Wheel Transportation Research Procedia. 20, 463-467 (2017)

5. P. Kotek, M. Kováč, Comparison of Valuation of Skid Resistance of Pavements by two Device with Standard Methods Procedia Engineering. 111, 436-443 (2015)

6. S. Rajendran, S. Spurgeon, G. Tsampardoukas, R. Hampson, Time-Varying Sliding Mode Control for ABS Control of an Electric Car. IFAC-PapersOnLine, 50, issue 1, pp. 8490-8495 (2017).

7. T.M. Caldwell, T.D. Murphey, Switching mode generation and optimal estimation with application to skid-steering Automatica. 47, Issue 1, pp. 50-64 (2011)

8. R. Ghandour, A. Victorino, A. Charara, D. Lechner, A vehicle skid indicator based on maximum friction estimation IFAC Proceedings Volumes. 44, issue 1, pp. 2272-2277 (2011)

9. S. Mavromatis, A. Laiou, G. Yannis, Safety assessment of control design parameters through vehicle dynamics model. Acc. Anal. \& Prevent., 125, pp. 330-335 (2019)

10. V.Y. Zadvornov, A.V. Kochetkov, L.V. Yankovskij, V.A. Chudinov, Natural Experiment by Deinition of the Qualitative Picture of Process of Slipping of the Wheel of the Car Road Laboratory. Res. \& Develop. in Mat. Scie. (2019) doi:10.31031/RDMS.2019.10.000739 